\title{
Recruitment and Selection of Dual-qualification Nursing Teachers: A Fuzzy Analytic Hierarchy Process Approach
}

\author{
Honglin Chen, Xia Li, Jianghua Zhu, Liren Li \\ Nantong University, Qixiu Road 19\#, Nantong city, Jiangsu province, PR China \\ Corresponding author is Liren $\mathrm{Li}$
}

\begin{abstract}
Dual-qualification nursing teachers are nurses who both teach and practice. However, it is still an unresolved issue to recruit and select a high-quality dual-qualification nursing teacher. This paper sets up a comprehensive assessment system model for dual-qualification nursing teacher recruitment, which was built by analytic hierarchy process (AHP). The model includes four sides such as biographical analysis, theoretical knowledge examination, clinical nursing skills assessment, and interview and lecture. Then the weight coefficients of indexes are determined by AHP. It provides a quantitative analyzing method for dualqualification nursing teacher recruitment.
\end{abstract}

KEYWORD: Dual-qualification nursing teacher; Recruitment; Quantitative analyzing method; Analytic hierarchy process

\section{INTRODUCTION}

Over the last three decades, nursing education has developed rapidly alongside world economic expansion. Many countries have experienced considerable reform within nursing education systems. In the People's Republic of China, the National Health and Family Planning Commission (NHFPC) raised to build the dual-qualification nursing teacher team in nursing education reform and development plan.[1] Dual-qualification nursing teacher was defined as nurse who both teach and practice. Dual-qualification nursing teacher perform a critical function in helping students to bridge the gap between theory and practice.[2] Dualqualification nursing teacher is very important in nursing career education. However, there is an insufficient number of Dual-qualification nursing teacher with adequate qualifications. And, How to recruit a qualified Dual-qualification nursing teacher is still an unresolved issue.

The analytic hierarchy process (AHP) is a multicriteria decision-making approach combining qualitative and quantitative analysis, based on mathematics and psychology. It was put forward by Thomas L. Saaty - a famous America operational in the 1970s. The method resolves the decision problem into different levels of structure model

Grant Support: Jiangsu Province Research Projects of Higher

Education Reform (2013JSJG235) according to target strata, criterion strata and index strata, then compares indexes of each level and formats comparative matrixes. It has particular application in a wide variety of decision situations, in fields such as government, business, industry, healthcare, and education.[3]

In this paper, we are trying to use AHP to set up a comprehensive assessment system model for dualqualification nursing teacher recruitment.

\section{RECRUITMENT OF DUAL-QUALIFICATION NURSING TEACHER DECISION MODEL BY AHP}

\subsection{Establishment of index system}

There are some basic principles followed when establish a system of evaluation index, such as concise and easy to operation, correlation and accuracy, hierarchy and aggregation. Based on the above aims and principles, the paper decomposes the factors of comprehensive assessment for dualqualification nursing teacher recruitment into 3 hierarchies: goal layer, criterion layer and index layer. The goal layer is the evaluation of dualqualification nursing teacher ability. The criterion layer (first grade index) includes biographical analysis, theoretical knowledge examination, clinical nursing skills assessment, and interview and lecture. The index layer (second index) includes educational background, academic achievement, professional 
knowledge, educational theory, research capacity, assessment capacity, intervention capacity, morphology and appearance, expression skills, and teaching skills. The assessment index system was shown in table 1 .

Table 1. Recruitment of dual-qualification nursing teachers decision model

\begin{tabular}{|c|c|c|}
\hline Goal: A & Criterion Layer: B & Index layer: $\mathrm{C}$ \\
\hline \multirow{10}{*}{$\begin{array}{l}\text { Recruitment of dual-qualification nursing } \\
\text { teachers decision model }\end{array}$} & \multirow{2}{*}{$\begin{array}{c}\text { B1 } \\
\text { Biographical analysis }\end{array}$} & C11 Educational background \\
\hline & & C12 Academic achievement \\
\hline & \multirow{3}{*}{$\begin{array}{c}\text { B2 } \\
\text { Theoretical knowledge examination }\end{array}$} & C21 Professional knowledge \\
\hline & & C22 Educational theory \\
\hline & & C23 Research capacity \\
\hline & \multirow{2}{*}{$\begin{array}{c}\text { B3 } \\
\text { Clinical nursing skills assessment }\end{array}$} & C31 Assessment capacity \\
\hline & & C32 Intervention capacity \\
\hline & \multirow{3}{*}{$\begin{array}{c}\mathrm{B} 4 \\
\text { Interview and lecture }\end{array}$} & C41 Morphology and appearance \\
\hline & & C42 Expression skills \\
\hline & & C43 Teaching skills \\
\hline
\end{tabular}

\subsection{Calculation of index weight}

According to the hierarchical structure of the evaluation index system of dual-qualification nursing teacher recruitment, we can construct the judgment matrix by Yaahp software (version 7.5. http://www.yaahp.cn/). The experts construct comparative matrix by 1-9 scale method.[4] If $i$ and $\mathrm{j}$ are equally important and is rated at 1 ; if $\mathrm{i}$ is extremely important than $\mathrm{j}$ is valued at 9 (table 2 ).

Table 2. Meaning of 1-9 scale method

\begin{tabular}{|l|l|}
\hline Valuation of $\mathrm{C}_{\mathrm{ij}}$ & Definition \\
\hline 1 & $\mathrm{i}$ and $\mathrm{j}$ are equally important \\
\hline 3 & $\mathrm{i}$ is a little importance than $\mathrm{j}$ \\
\hline 5 & i is obvious important than $\mathrm{j}$ \\
\hline 7 & i is strong important than $\mathrm{j}$ \\
\hline 9 & i is extremely important than $\mathrm{j}$ \\
\hline $2,4,6,8$ & intermediate value of adjacent judgments \\
\hline $\begin{array}{l}\text { Reciprocals of } \\
\text { above }\end{array}$ & $\begin{array}{l}\mathrm{j} \text { has the reciprocal value when } \\
\text { compared with } \mathrm{i}\end{array}$ \\
\hline
\end{tabular}

The comparative matrix of criterion layer compared with goal layer was shown in table 3.

Table 3 Pairwise comparative matrix of the main criteria with respect to A-B (consistency test, $\mathrm{CR}=0.0227,<0.10$ )

\begin{tabular}{|c|c|c|c|c|c|}
\hline A-B & B1 & B2 & B3 & B4 & wi \\
\hline B1 & $1 / 1$ & 2 & 2 & $1 / 2$ & 0.2792 \\
\hline B2 & $1 / 2$ & $1 / 1$ & $1 / 1$ & $1 / 2$ & 0.1646 \\
\hline B3 & $1 / 2$ & $1 / 1$ & $1 / 1$ & $1 / 2$ & 0.1646 \\
\hline B4 & $2 / 1$ & $2 / 1$ & $2 / 1$ & $1 / 1$ & 0.3917 \\
\hline
\end{tabular}

The relative weight of vectors was given directly by Yaahp software. The wi values are 0.2792 , $0.1646,0.1646$, and 0.3917 , respectively. Similarly, the comparative matrix of index layer compared with criterion layer was shown in table 4.

The wi values are $0.3333,0.6667 ; 0.3338$, $0.1416,0.5247 ; 0.1667,0.8333 ; 0.1638,0.5390$, 0.2973 , respectively. And the wz values of the whole model are $0.0931,0.1861,0.0549,0.0233,0.0864$, $0.0274,0.1372,0.0641,0.2111$, and 0.1164 , respectively.

Table 4 Pairwise comparative matrix of the main criteria with respect to B-C (consistency test, B1-C CR=0.0000, < 0.10; B2C $\mathrm{CR}=0.0517$, < 0.10; $\mathrm{B} 3-\mathrm{C} \mathrm{CR}=0.0000,<0.10$; $\mathrm{B} 4-\mathrm{C}$ $\mathrm{CR}=0.0089,<0.10)$

\begin{tabular}{|c|c|c|c|c|c|}
\hline B1-C & C11 & C12 & & w1 & wz \\
\hline C11 & $1 / 1$ & $1 / 2$ & & 0.3333 & 0.0931 \\
\hline C12 & $2 / 1$ & $1 / 1$ & & 0.6667 & 0.1861 \\
\hline & & & & & \\
\hline B2-C & $\mathrm{C} 21$ & $\mathrm{C} 22$ & $\mathrm{C} 23$ & w2 & \\
\hline $\mathrm{C} 21$ & $1 / 1$ & $3 / 1$ & $1 / 2$ & 0.3338 & 0.0549 \\
\hline $\mathrm{C} 22$ & $1 / 3$ & $1 / 1$ & $1 / 3$ & 0.1416 & 0.0233 \\
\hline $\mathrm{C} 23$ & $2 / 1$ & $3 / 1$ & $1 / 1$ & 0.5247 & 0.0864 \\
\hline & & & & & \\
\hline B3-C & $\mathrm{C} 31$ & $\mathrm{C} 32$ & & $\mathrm{w} 3$ & \\
\hline $\mathrm{C} 31$ & $1 / 1$ & $1 / 5$ & & 0.1667 & 0.0274 \\
\hline $\mathrm{C} 32$ & $5 / 1$ & $1 / 1$ & & 0.8333 & 0.1372 \\
\hline & & & & & \\
\hline B4-C & $\mathrm{C} 41$ & $\mathrm{C} 42$ & $\mathrm{C} 43$ & $\mathrm{w} 4$ & \\
\hline $\mathrm{C} 41$ & $1 / 1$ & $1 / 3$ & $1 / 2$ & 0.1638 & 0.0641 \\
\hline $\mathrm{C} 42$ & $3 / 1$ & $1 / 1$ & $2 / 1$ & 0.5390 & 0.2111 \\
\hline $\mathrm{C} 43$ & $2 / 1$ & $1 / 2$ & $1 / 1$ & 0.2973 & 0.1164 \\
\hline
\end{tabular}




\subsection{Consistency validation}

In order to guarantee the conclusion reasonable by applying AHP, we use Consistency Ratio (CR) as indicator to measure the deviation consistency of judgment matrix. If the $\mathrm{CR}$ is greater than 0.1 , the judgments are untrustworthy because they are too close for comfort to randomness and the exercise is valueless or must be repeated.[5]

The Yaahp software also gives the CR directly. The CR value of criterion layer compared with goal layer is $0.0227<0.10$, which indicate good consistency. The $\mathrm{CR}$ values of index layer compared with criterion layer are $0.0000,0.0517,0.0000$, and
0.0089 , respectively. They all less than 0.10 , and indicate good consistency.

\section{EMPIRICAL STUDY}

To recruit a dual-qualification nursing teacher, there are three candidates participate in the recruitment. We used the above AHP and fuzzy comprehensive evaluation method for quantitative evaluation of the three candidates. The model was shown in figure 1.

Five experts assessed three candidates alone by the model. The scores of three candidates were listed in the table 5 .

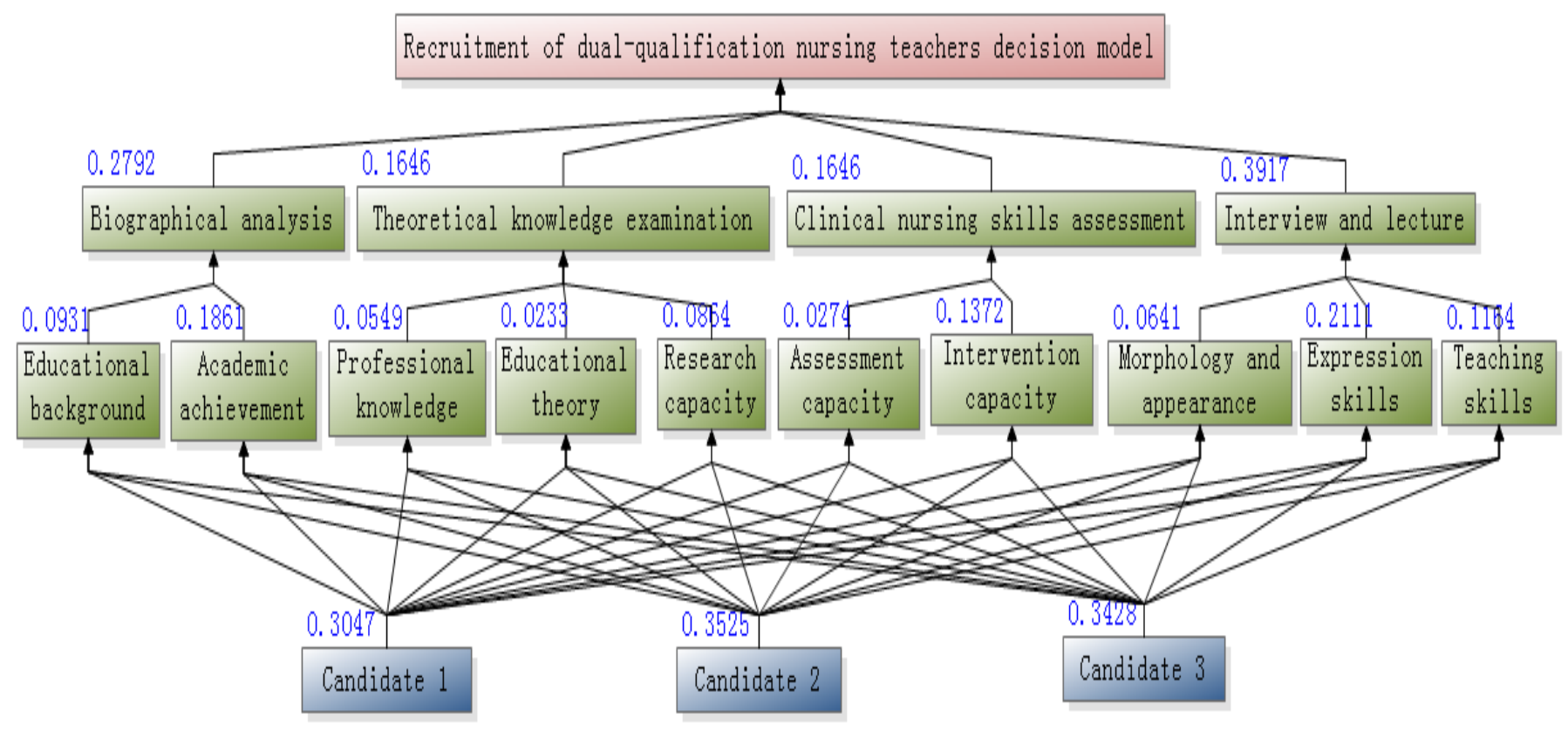

Figure. 1 Recruitment of dual-qualification nursing teachers decision model

Table 5 Scores of three candidates by 5 experts (E)

\begin{tabular}{|c|c|c|c|c|c|c|c|c|c|c|c|c|c|c|c|c|c|c|c|}
\hline \multirow{2}{*}{ B } & \multirow{2}{*}{$\mathrm{C}$} & \multicolumn{6}{|c|}{ Candidate 1} & \multicolumn{6}{|c|}{ Candidate 2} & \multicolumn{6}{|c|}{ Candidate 3} \\
\hline & & E1 & $\mathrm{E} 2$ & E3 & E4 & E5 & Mean & E1 & E2 & E3 & E4 & E5 & Mean & E1 & E2 & E3 & E4 & E5 & Mean \\
\hline \multirow{2}{*}{ B1 } & $\mathrm{C} 11$ & 5 & 5 & 4 & 4 & 5 & 4.6 & 3 & 4 & 3 & 4 & 4 & 3.6 & 4 & 3 & 4 & 4 & 5 & 4 \\
\hline & $\mathrm{C} 12$ & 5 & 5 & 4 & 5 & 5 & 4.8 & 3 & 3 & 3 & 3 & 3 & 3 & 4 & 3 & 3 & 4 & 3 & 3.4 \\
\hline \multirow{3}{*}{ B2 } & $\mathrm{C} 21$ & 4 & 5 & 5 & 4 & 3 & 4.2 & 4 & 3 & 4 & 3 & 4 & 3.6 & 3 & 4 & 4 & 4 & 3 & 3.6 \\
\hline & $\mathrm{C} 22$ & 4 & 5 & 5 & 4 & 4 & 4.4 & 3 & 4 & 5 & 4 & 4 & 4 & 3 & 4 & 3 & 4 & 4 & 3.6 \\
\hline & C23 & 5 & 5 & 4 & 5 & 4 & 4.6 & 3 & 4 & 5 & 4 & 4 & 4 & 4 & 5 & 5 & 4 & 5 & 4.6 \\
\hline \multirow{2}{*}{ B3 } & C31 & 4 & 5 & 4 & 4 & 4 & 4.2 & 5 & 4 & 5 & 5 & 5 & 4.8 & 3 & 4 & 4 & 4 & 3 & 3.6 \\
\hline & C32 & 4 & 5 & 5 & 5 & 5 & 4.8 & 4 & 5 & 4 & 5 & 4 & 4.4 & 5 & 5 & 4 & 4 & 4 & 4.4 \\
\hline \multirow{3}{*}{ B4 } & C41 & 5 & 5 & 5 & 5 & 5 & 5 & 3 & 3 & 4 & 3 & 4 & 3.4 & 3 & 4 & 4 & 4 & 5 & 4 \\
\hline & C42 & 5 & 5 & 5 & 5 & 5 & 5 & 5 & 4 & 4 & 3 & 4 & 4 & 3 & 4 & 4 & 4 & 4 & 3.8 \\
\hline & C43 & 4 & 5 & 5 & 5 & 4 & 4.6 & 5 & 4 & 4 & 4 & 4 & 4.2 & 4 & 3 & 3 & 4 & 3 & 3.4 \\
\hline
\end{tabular}

Five experts assessed three candidates alone by the model. The scores of three candidates were listed in the table 5 . The mean scores $(\mathrm{H})$ of candidate 1 were 4.6, 4.8, 4.2, 4.4, 4.6, 4.2, 4.8, 5, 5, and 4.6, respectively. According to the formula $\left(\mathrm{z}=\mathrm{H}^{*} \mathrm{w}\right)$, we calculated the score was 4.73716. Similarly, we calculated the scores for candidate 2 and candidate 3 were 3.81632 and 3.84076 , respectively. Candidate 1 received the highest score of the three candidates.

So, candidate 1 was recruited as a dualqualification nursing teacher. 


\section{CONCLUSION}

This paper sets up a comprehensive assessment system model for dual-qualification nursing teacher recruitment determined by AHP. The model provides a quantitative analyzing method for dualqualification nursing teacher recruitment.

\section{REFERENCES}

[1] National Health and Family Planning Commission (NHFPC) of Nursing, pharmacy and other medical education reform and development plan. http://www.moh.gov.cn/mohbgt/pw10407/200804/27058. html. Assessed at May 20, 2014.

[2] $\mathrm{Wu} \mathrm{Y,} \mathrm{Liu} \mathrm{H,} \mathrm{He} \mathrm{H.} \mathrm{Stressors} \mathrm{of} \mathrm{dual-qualification}$ nursing teachers in the ChengDu-ChongQing economic zone of China--a qualitative study. Nurse Educ Today. 2013; 33(12):1496-500.

[3] Forman, Ernest H, Saul I Gass. The analytical hierarchy process - an exposition. Operations Research. 2001; 49 (4):469-87.

[4] Zhiyong Zhang, Xinbao Liu, Shanlin Yang. A Note on the 1-9 Scale and Index Scale in AHP. Communications in Computer and Information Science. 2009; 35:630-4.

[5] José antonio Alonso, $\mathrm{m}^{\mathrm{a}}$ teresa lamata. consistency in the analytic hierarchy process: a new approach. international journal of uncertainty. 2006; 14(4): 445-59. 